\title{
Applying for professional positions
}

\author{
By Suzanne T. Larsen and Joan S. McConkey
}

\section{How to present your assets in the most favorable light}

$\mathbf{A}$ $s$ we review applications for professional positions, we find that many applicants do not understand the importance of creating a complete, well-organized, professional-looking dossier. Individuals who might have the qualifications for a position often do not make it past the first review of applications because they do not present themselves weil.

We identify problems we have seen repeatedly in applications for our positions, as well as present suggestions to help you increase your chances of being considered for a position on the strength of your documentation.

\section{The position announcement}

Read the position announcement carefully, phrase by phrase. Take it seriously. It has been carefully written to attract an individual with specific qualifications to the position. If you do not have the skills, education, or experience identified as requirements for the position, do not apply.

It is a good idea to request a position description prior to making application. These are usually far more complete and detailed than the position announcement and will provide more insight into the position. Plan for your application to arrive prior to the closing date in the announcement.

\section{The application}

The application should consist of a cover letter and a resume or vita. If an agency application form is required, it will usually be indicated in the position announcement and you should ask to have it sent to you. Submit your documents on clean, good-quality paper that will photocopy well, since application documents may be photocopied for each search committee member. Search committee members are unlikely to see special colors or carefully prepared notebooks with various-sized pages. If there is more than one position open at an institution for which you wish to apply, send separate cover letters and resumes for each position. Different search committees may be involved and you will want to make your cover letter position-specific.

The advent of word processing has created a new set of potential pitfalls in addition to the standard dilemma of how to create a resume and cover letter that will be well received. It is especially important to proofread all your documents thoroughly, especially if you are amending your resume and cover letter each time you apply for a position. It is disconcerting to receive a cover letter correctly addressed but with a different name in the "Dear ..." line, probably left over from another application.

A. The cover letter. The cover letter is your first, and possibly your most important communication with the search committee or personnel officer. Selection of candidates to be interviewed will be based very heavily on this document. The letter is usually considered an example of your written communication skills, so treat it that way. Attention to detail is mandatory. To state the obvious (yet something that is overlooked by too many applicants), spelling, grammar, organization, and format are all of great importance.

\footnotetext{
Suzanne T. Larsen is bead of the Earth Sciences Library and Joan S. McConkey is associate director for administrative services in the University Libraries at the University of Colorado at Boulder; e-mail: larsens@spot.colorado.edu, mcconkej@spot.colorado.edu
} 
A cover letter should address the position for which you are applying; it should not be generic. Generic application letters only show that you are applying widely and may not be particularly interested in the position at hand. If an individual is listed in the position announcement, address the letter to that individual. Identify the position you are applying for at the beginning of the letter. An institution may have several openings at the same time, and this will avoid any confusion. It is also a good idea to indicate in the cover letter where you saw the position advertised.

Usually the position announcement identifies required skills or experience and more specific, desirable characteristics. Be sure to address each of those items in your cover letter even if you feel that they are covered in the resume. There is always the possibility your qualifications may be missed or misinterpreted if they appear only in the resume. It never hurts to restate the obvious.

If you possess any of the qualifications indicated as desirable in the position announcement, be sure to identify them. Meeting the requirements for the position will get you into the pool of candidates, but having the skills and qualifications identified as desirable will usually put you at the top of the list. This is especially true when the requirements are very broad, such as those for entry-level positions.

Use the cover letter to emphasize specifically how well you fit the position as identified in the announcement and/or position description. Use it to flesh out important abbreviated statements on the resume or vita. Give complete, concise information. Two pages should be the maximum length.

While the cover letter is the place to emphasize what you do well, do not claim to have skills you do not have. The cover letter and the resume should be connected. For example, if the position requires supervisory experience, identify the type and amount of experience you have in the cover letter. Your resume should corroborate the statements in your letter.

Think seriously before attempting to use humor in your cover letter. It is rarely effective in this context and will probably not attract the kind of attention you are seeking.

B. Resume/vita. Job announcements will usually request either a vita or a resume. In general, a vita is an outline of a person's experience, education, publications, and presentations. A resume may also include brief descrip- tions of duties in previous positions, a full chronological accounting for time completed after the professional degree, and a list of references with current addresses and telephone numbers. The greater detail in the resume is usually preferable for positions above the beginning level, and it is almost always necessary to submit the names of references.

Unlike the cover letter, the resume may be generic. However, you may choose to change it according to the requirements of specific positions to emphasize certain aspects of your work or educational history. If you decide to customize your resume, be careful not to send that same version in application for another position which has a different focus.

You should include dates on the resume so that years of experience, education, and other statements can be substantiated. Organize the resume so that these dates are easily identified. Usually a job title is not sufficient to describe the duties performed in the position. A brief summary of duties for each position you held is desirable. Outline format or the use of typographical "bullets" is preferable to a lengthy paragraph. Just hit the high points.

You will need to decide how far back to extend your employment history or what to include. The job you had in the fast food outlet in high school is not of great interest; on the other hand, a clerical position where you learned computer skills or word processing might help your cause. What you include may well depend on the type and level of position for which you are applying.

It is important to account in some way for any obvious gaps in your work record. For example, if you were touring Europe for six months following your last position, state that in the cover letter. Relevant volunteer work should also be included.

For positions in academic libraries, it is especially important to include any publications or formal presentations. If the publications are relevant to the position for which you are applying, send copies with your application. Only include in-house material from your current position if it is directly pertinent. Membership, activities, and offices held in professional organizations should also be included.

C. References. Choose your references carefully. These should be people who have recent knowledge of your work. Ask those you wish to use as references in advance for permission to use their names. Use references who 
can substantiate statements in your cover letter and resume. Supply them with an up-to-date copy of your resume, copies of the announcements of positions for which you are applying, and the cover letters you are writing. It is best to select references who can comment specifically on the required and desirable aspects of the position.

Include your direct supervisor as a reference, if possible. It is understandable that this may not be comfortable for you at the onset of the application process, but keep in mind that if you are being seriously considered for a position, a reference from your supervisor may be required.

D. Formatting the documents. Use a la ser printer if at all possible. It is no longer necessary to get your resume typeset to make it look professionally done. Do not try to cram everything into the cover letter and resume by using small print and narrow margins. The appearance of these documents is almost as important as their content.

\section{Affirmative action provisions}

It is appropriate not to supply race, age, religion, marital status, and other information that is not to be used in hiring decisions. Do, however, fill out any affirmative action forms that are sent to you and submit them as directed. Most public colleges and universities particularly encourage women, ethnic minorities, disabled persons, and veterans to apply for their positions.

\section{Conclusion}

All of the areas we have discussed here address the problems we have found with applications we've received. It is much easier to give serious consideration to a clear, well-organized, well-written, complete dossier than to take the time to sort through a messy and poorly prepared one. Your chances of being considered for an interview will increase greatly by taking the application process seriously and tailoring your application to the position requirements.
(Research cont. from page 414)

reer. There should be a research dimension (a genuine and in-depth explanation on how to locate and critically evaluate resources) in a host of classes and throughout the academy's disciplines.

Such a restructuring of our approach-a commitment to teaching research in much the same way progressive institutions already teach writing-wouldn't immediately bring a radical and revolutionary change. But it could mean the beginning of a new way of looking at research and research skills in the totality of the educational enterprise. At the very least, colleges and universities might add a skilled familiarity with research and information retrieval to the litany of competencies and skills they require of their graduates. Deans might begin to scrutinize a departmental major in light of its commitment to quality student research as much as the department's teaching accomplishments or breadth of course coverage. Outside evaluating boards might even start to ask pointed and perhaps embarrassing questions about the kinds of steps the institution is taking to equip its students for the information age. And perhaps most importantly of all, librarians equipped with a more comprehensive, holistic vision of their own role in the educational enterprise could really begin to engage students in the wonders of scholarly research and to empower students to function in the increasingly complex, if troublesome, information era.

Like writing, research merits a more thorough and comprehensive commitment. Colleges and universities have to replace their present well-intentioned approach to research instruction with a sustained, comprehensive visionone that teaches research skills in a variety of classes and contexts. For today's academic climate, the old we-are-there-whenever-you-needus $\mathrm{BI}$ approach is just too ineffective and truncated.

The importance of knowing how to tap into the world of information, of engaging oneself in the world of scholarly conversation, and of learning how to critically evaluate the conflicting arguments and claims of varied sources cannot be overestimated. And it can't be left to happenstance. Such skills have to be taught, and taught by those who know most about them. Just as higher education has had the courage to tackle the problem of writing aggressively, colleges and universities should now address the coming demands of the information age. It's time we taught research across and throughout the curriculum. 